\title{
Research on the Mixed English Teaching Model of Vocational College under the Background of "Internet Plus"
}

\author{
Xin Wang \\ Department of Basic Education, Urumqi Vocational University, Urumqi, Xinjiang, 830000, China \\ 2391037196@qq.com
}

Keywords: "Internet plus", higher vocational English teaching, mixed teaching mode

\begin{abstract}
With the advent of "Internet plus" era, English teaching in higher vocational education has been greatly enriched, which has laid a foundation for the construction of mixed teaching mode. This paper first briefly introduces the basic concepts of "Internet plus" and mixed teaching. Meanwhile, it discusses the existing problems of English teaching in higher vocational colleges as well as opportunities brought by the "Internet plus" era to the reform of English teaching in higher vocational colleges. On this basis, some suggestions on the construction of mixed vocational English teaching model are put forward.
\end{abstract}

\section{Introduction}

In the era of "Internet plus", the mode of "E-Learning" has completely changed the traditional classroom teaching purpose and form with the rapid development of education informatization. Under such circumstances, advanced education methods, such as "micro class" and "flipped classroom" have been widely applied in higher vocational English teaching, which can play an important role in improving teaching effect. With the wide promotion of "Internet plus education", continuous deepening of teaching research and practice, it is necessary to integrate all kinds of teaching methods and construct the mixed teaching mode, so as to further enhance the level of higher vocational English teaching.

\section{2. "Internet plus" and mixed teaching}

\section{1 "Internet plus education"}

Since the concept of "Internet plus" has been proposed in the fifth session of the mobile Internet expo, its influence immediately spread to various fields of industry, business, finance, education etc.. In these cases, "Internet plus education" is a product of the Internet technology and modern education integration. What will be produced by the combination of the two? The answer given by Wang Qiang, chairman of ZUOYE network, is that: "Internet plus education equals to smart education". In 2015 government work report, "Internet plus" was put on the agenda, which has accelerated the development of "Internet plus education". In this case, integration of education and information technology, and the network will become the major development direction in the future. With the support of various networking tools, the limitations of traditional classroom teaching will be completely broken, so as to realize high sharing of educational resources, educational equipment and excellent educational talents. Moreover, the openness and interactivity of network can also help to facilitate communication and exchanges between teachers and parents, teachers and students, parents and students. Moreover, this mode can help teachers and parents better understand the needs of students' learning and growth, thus facilitating their knowledge and intellectual growth. Therefore, the "Internet plus" era provides unprecedented opportunities and motivation for education reform [1]. 


\subsection{Mixed teaching}

The generalized mixed teaching is the integration of all kinds of teaching methods. Through giving full play to the advantages and characteristics of each teaching method, it helps to cultivate students' independent learning capability and innovative ability, thus ensuring the pertinence and effectiveness of teaching. In the "Internet plus" era, mixed teaching mode refers to the specific combination of online teaching and offline teaching. It aims to integrate advantages of traditional education and modern educational technology, so as to promote the organic combination of the two. Ultimately, it's to construct a complete teaching mode and provide guidance for teaching practice. The construction of the mixed teaching mode mainly complies with the following basic principles: (1) Student-based principle. It pays more attention to the participation of learners; (2) Building a progressive teaching process based on the general rules of knowledge accumulation; (3) Adopting targeted teaching method according to differences of learners and learning conditions; (4) Providing guidance and help for the autonomous learning and extracurricular activities. In this principle system, integration of online teaching and offline teaching can not be implemented superficially, but should focus on the combination of teaching content and teaching methods. Online teaching shall be an indispensable link of teaching, instead of supplement to classroom teaching. In addition, it's imperative to analyze from the existing problems in higher vocational English teaching, so as to clarify the goal of the mixed teaching reform and the construction direction of the teaching model [2].

\section{Present situation and existing problems of English teaching in higher vocational colleges}

\subsection{Lagged teaching concept}

Since the implementation of the new curriculum reform, according to the Basic Requirements for The Teaching of English Courses in Higher Vocational and Technical Colleges issued by Ministry of Education, students shall be required to have the ability to apply the basic knowledge and skills of English in the course of English Teaching in Higher Vocational Education. Moreover, they shall be able to complete simple translation of English with the help of dictionaries and professional information. What's more, they ought to have fluent oral or written expression in foreign communication activities. After the completion of the teaching task, the students should be able to reach the level A or B level of the College English application competence test. The new goal of higher vocational English teaching has given the new mission of English teaching. Only by thoroughly changing the teaching concept of the traditional examination oriented education mode can we achieve the goal of cultivating innovative and applied talents. However, from perspective of current situation of English teaching reform in higher vocational colleges, the traditional teaching idea still has a great influence on the practical teaching activities. Moreover, some teachers intentionally regard the basic knowledge of English teaching as the main teaching contents, who would like to improve students' English learning achievement by rote memorization and excessive assignments. Under such circumstances, students' oral communicative competence and language application ability can not be exercised or improved, so it is difficult to really achieve the requirements of new curriculum reform to higher vocational English teaching. In addition, the influence of traditional teaching concept is also demonstrated as that teachers do not pay enough attention to online teaching resources, and the utilization rate is low. What's worse, they would not apply information technology teaching unless they were informed to do it or they have to record some public classes. In usual teaching, they seldom apply information technology [3].

\subsection{Single teaching methods}

Higher vocational English is a public basic course, which is closely related to Accounting English, Business English and computer courses. It is an important foundation for learning other courses. At the same time, the development of English public class in higher vocational college is also influenced by students' English learning in high school. Due to the poor overall quality of students in higher 
vocational schools, English discipline is generally weak discipline for students. Compared with ordinary universities, students' vocabulary accumulation and grammatical basis are relatively weak, and they lack interest in learning English. In this case, it is more necessary for higher vocational English teachers to adopt diversified teaching methods and improve teaching pertinence, so as to help students improve basic knowledge and skills as soon as possible. Only in this way can this mode meet students' career development needs and cultivate their interest in learning English. However, the English teaching methods in higher vocational colleges is relatively simple according to the actual teaching implementation. It still takes the traditional classroom teaching as the main form, in which teachers arrange the teaching contents according to the requirements of textbooks and syllabus, and carries out training of listening, speaking, reading and writing step by step. Moreover, in the process of classroom teaching, teachers' explanations still occupy a large proportion and students have less time for interaction, let also oral communication training that imitates professional situations. Under such circumstances, students seriously lack learning motivation and interest in English learning. As a result, learning effect can be hardly seen. Therefore, it's imperative to improve the single teaching mode as soon as possible [4].

\subsection{Insufficient learning atmosphere}

Under the influence of lagged teaching idea and single teaching form, Internet resources can hardly be utilized in higher vocational English teaching. Meanwhile, the role played by modern educational technology is limited, so that the atmosphere of classroom learning is inadequate. Students lack the support of curriculum resources in self-directed inquiry learning. In class, their information resources are limited to the PPT courseware made by teachers. However, the PPT courseware lacks novelty, which fails to comb out classroom knowledge structure and teaching process. In this case, students have some blindness in independent learning and interactive inquiry learning, so the effect is far from satisfactory. On the other hand, due to the lack of teachers' guidance of English learning methods and basic knowledge accumulation methods, students have low efficiency in autonomous learning. A variety of reasons lead to their lack of confidence in English learning, which is easy to increase their inertia of English learning. In this case, students often sleep, chat or handle other subjects in class, thus causing serious lack of expected learning atmosphere of English classroom. According to results displayed in the English classroom teaching in a province of 13 vocational colleges, students have generally low satisfaction of English classroom teaching. Those who are "not that satisfied" or "dissatisfied" accounted for 37\%. In addition, a survey about "learning communication in class" showed that $71 \%$ of students expressed less in learning communication, thus failing to play a positive role among students [5].

\section{Opportunities for the construction of mixed English teaching model in higher vocational colleges brought by "Internet plus" era}

\subsection{Support of modern network resource platform}

With the advent of "Internet plus" era, network information technology has been integrated into all aspects of people's life and learning. The wide spread of intelligent terminal equipment enables vocational college students to make full use of the intelligent mobile phone and tablet computer to get the learning resources in the network. In this case, the network resource platform has also been developing rapidly. Various educational resource websites, We-Chat platforms, English cloud classes, etc. have provided more acquisition channels of learning resources for students. Moreover, many web resources platforms provide students with opportunities to communicate with experts, teachers and star teachers. Students can consult their learning problems at any time, grasp the most advanced learning methods and improve learning efficiency. The construction and application of the network resource platform completely break the limitation of the traditional education, and provide a good help to promote the development of the student-oriented education. Traditional textbooks, CDs and libraries are no longer the only way for students to acquire learning resources. They don't need to 
spend much time and energy in finding learning resources and running to the library. The network resource platform provides a quick search function for students, which can help students find the target resources in the shortest time. What's more, the network learning resources are provided in various forms, which can be also quite expressive. Students can acquire basic knowledge of English through a variety of resources, such as words, pictures, audio, video and other forms, according to their interests and hobbies, thus greatly alleviating the baldness of the basic knowledge of English [6].

\subsection{Support of modern educational technology}

In view of the poor English foundation of higher vocational students and their lack of autonomous learning ability, the application of modern educational technology in the classroom teaching helps to break through the bottleneck, which can enrich the teaching methods and means of teachers and improve teaching efficiency, so as to promote the students' English level in a short period of time [7]. In the traditional classroom teaching, although multimedia equipment has also been applied to a certain extent, most of teachers still explain key problems and exercises by blackboard writing, which can account for time. Moreover, the blackboard can not be reused immediately, which may increase the repeated work of teachers. In addition, the traditional explanation form can hardly achieve the complete expression and visual display of the knowledge structure in the class, so it may be difficult for students to understand and memorize. With the support of modern educational technology, the teaching and testing links of basic knowledge can be arranged in online classroom. Through online interaction and game interaction, it can help students reduce the difficulty of memorizing vocabulary and practicing oral English. The online classroom can automatically record students' learning status and test results. This channel can help teachers understand the weak links of students in self-study, so as to adopt targeted teaching methods. In this case, teachers can solve difficult problems of students in the class and cultivate students' overall English application ability, thus meeting higher requirements of higher vocational English by the new curriculum standard.

\subsection{Support of "Internet plus" education concept}

"Internet plus education" attaches great importance to the student-oriented idea, which respects students' objective cognitive rules. Through reshaping the classroom teaching role, students are regarded as the main body of teaching. And teachers should play the role of learning guider and supporter, who especially provide teaching resources for students and guide students in self-study. Through constructing a harmonious and equal relationship between teachers and students, teachers and students can communicate in an equal manner, and jointly complete the inquiry of teaching content. Online platform provides more channels for teacher-student communication, which can enhance the timeliness of communication and reduce the gap between teachers and students. In this situation, students and teachers can make smooth communication on We-Chat, QQ and other learning platforms. The spread of "Internet plus education" concept is beneficial to weaken the adverse effects of traditional education in higher vocational English teaching, which can provide the impetus for the innovation of teaching mode and teaching methods.

\section{D. Countermeasures to build a mixed English teaching model in higher vocational Education based on the background of "Internet plus"}

\subsection{Build the U-Learning teaching environment}

U-Learning means ubiquitous learning, which is a learning method that enables learners to obtain useful information and communicate at anytime and anywhere under the support of information technology. "Internet plus" era makes it possible to build U-Learning teaching environment. Teachers can assign learning tasks for students by use of the diversified information education resources and teaching tools. Form another perspective, teachers can provide students with learning resources, so as to guide them for autonomous learning and improve their efficiency by scientific methods. U-Learning contains four layers of meaning, namely, "Anyone", "Anytime", "Anywhere" and 
"Anydevice", that is, "4A" teaching environment. In this environment, the online teaching resources are highly shared, which can be utilized by any one of learners. This mode supports users to learn by any methods at any time and any place, so that students in higher vocational colleges can make full use of fragmented time, thus compensating for their lack of basic knowledge skills.

At present, the basic level of English in higher vocational colleges is quite different. Under the traditional "big class teaching" mode, many students can't keep up with the teachers' teaching progress. In the teaching interaction and training links, they are too shy to practice oral expression and interact with teachers. It is difficult for teachers to find effective teaching methods to meet the actual needs of each student. In this case, the construction of the U-Learning teaching environment is of great significance. On the basis of syllabuses and textbooks, teachers can independently develop or download learning resources from the Internet, compile various forms of teaching courseware and put them in the campus network platform. Students can log on the campus network via the student ID and password. Then they can find the learning resources released by teachers in the corresponding directory. As a result, they can download this resources or learn online. Through watching teaching courseware and related video, students can make up for the loopholes in the learning process and have a more profound understanding of the knowledge taught in class. In addition, students can also test their self-study effect by random online test topics designed by teachers. By communicating with teachers, students can find out the problems in self-learning process, thus further promoting the competency of autonomous learning. In the "Internet plus" background, rich online resources have provided strong support for the construction of U-Learning teaching environment. Teachers can continuously introduce resources that can be used by students in the network resources, and make necessary improvement, so as to make it really helpful for students.

\subsection{Promotion of SPOC curriculum resources}

SPOC is the abbreviation of "Small Private Online Course", that is, small-scale restrictive online courses. It's the product formed on the basis of MOOC, which fully integrates the inquiry learning, personalized learning and writing learning. As a result, online curriculum is more targeted and curriculum form is more diverse. Meanwhile, this mode can make up the defects of the traditional courseware that does not support the interaction between teachers and students. The promotion of SPOC curriculum resources is an important prerequisite for the implementation of the flipped classroom teaching. In the "Internet plus" era, flipped class and teaching mode have been widely practiced in higher vocational English teaching, which have become a concentrated expression of "Internet plus education" concept. However, micro class can hardly realize the expected teaching effect due to low quality in the process of past flipped classroom teaching. In this case, the application of SPOC curriculum resources based on Internet platform can effectively solve this problem, and promote the dynamic development of fixed online classroom teaching, making it more suitable for students' needs in autonomous learning and interactive learning. And task-driven method is adopted to fully link the content of online courses with the English classroom teaching contents in higher vocational colleges. The construction of a new SPOC plus task-driven flipped classroom teaching is conducive to improving the actual teaching effect of flipped classroom teaching.

Under this mode, teachers can help the students to sort out the knowledge structure, clarify the purpose of learning and focus on the learning content by designing teaching plan, PPT and video etc. Through gradual guidance and self-check, teachers can ensure the effect of online curriculum resources. For example, teachers can underline "punctuality", "re-schedule" and "in advance" as the key words; and guide students to analyze and understand some sentences, such as "One of the cultural differences that tends to annoy Americans has to do with understanding of punctuality". By connecting with the words or sentences that have been learned before, the difficulty of understanding and remembering the key and difficult points can be reduced. For example, some words like "retell" and "replace" can be linked when learning the word "re-schedule". In addition, the student self-test card can also be designed to help students understand their self-learning ability more clearly. In this respect, it is necessary to control the difficulty of the test problems and gradually help students to improve their self-study ability. For example, in these courses, some T/F questions can be designed in 
the self-test card, such as "Indians are serious about time." and "Americans have a relaxed view of time.".

\subsection{Organic combination of various learning patterns}

The construction of mixed higher vocational English teaching mode under the "Internet plus" background calls for integrating two major categories of resources in human and network, so as to promote the organic integration of a variety of teaching patterns. "Internet plus education" is a kind of the "student-oriented" educational idea. However, teachers still play an important role in this pattern, who serve as the guide in students' autonomous learning. Teachers shall timely grasp the learning situation of the students and provide effective guidance. Under this requirement, teachers' application of online teaching resources can not be limited to the simple stage of teaching by using multimedia tools, such as microphones, PPT courseware and so on. Instead, teachers shall have a more profound understanding of Internet plus. Through integrating all the available resources and technically using various teaching methods, teachers shall try to realize a new teaching model of "one teaching network", "one mobile terminal" and selective teachers and learning resources, facilitating China’s education towards the 4.0 new era.

The integration of multiple learning modes mainly includes the following aspects: (1) Flipped classroom. With the gradual maturity of this teaching mode, the flipped classroom has been widely implemented in higher vocational English teaching. In such a teaching mode, students are the main body of the class, and teachers are the helper of students. In the process of building a mixed teaching model, the flipped classroom can exert an important influence on the establishment of new teacher-student relationship. Therefore, it is an important basis for integration of various teaching methods and learning mode; (2) Micro class. It is currently one of the most widely used online curriculum resources, which is featured with shortness. Micro class can complete an ingenious explanation of a specific knowledge in just a few minutes to ten minutes. Students can have online self-study via some videos. The main advantage of the course is that it can reflect the pertinence of the teaching and help students to solve the key and difficult problems in the course of learning. In addition, micro class can fully utilize educational resources and allow students to enjoy the charm of star teachers. Such contents are often interesting and attracting, which can arouse students' interest in learning; (3) Blog. Under the background of "Internet plus", blog has gradually become a popular application of online teaching mode. Its significance lies in strengthening the communication function and exchange function of online learning resources, so that the online learning can be more open and personalized, thus improving the efficiency of information transmission; (4) Online learning communities. Through We-Chat, forums and community platforms on the Internet, the online learning communities can be built to promote cooperative learning mode. In this case, students can make progress with each other and improve English learning ability together.

\subsection{Innovative application of traditional teaching resources}

In the process of constructing a mixed teaching mode of higher vocational English, teachers shall pay more attention to the innovative application of traditional teaching resources. Based on traditional teaching resources, they shall gradually develop online teaching resources and promote the organic integration of the two. For example, teachers can design the following teaching process in the integration of these teaching methods: (1) Preparation before class. The micro class is mainly adopted to assist students in self-learning before class. Extracting the representative knowledge content in the teaching material unit and designing the teaching task. Then teachers ought to make a 10-minute micro class. Students can complete preparation before class through watching and learning for many times; (2) In the process of classroom teaching, the teachers can refine the universal questions and make in-depth explanations according to the students' learning. What's more, teachers shall also carry out various forms of language training activities, so as to strengthen the application ability, English knowledge and skills of students. In the framework of teaching syllabus and teaching materials, appropriate extension is necessary; (3) After-class consolidation and practice. Teachers can design training exercises for students via blogs or We-Chat. They can also provide online 
resources for review and answer their questions. The practical activities in the teaching materials can be carried out online, thus providing more practical training opportunities for students.

On this basis, it can be seen that the traditional teaching resources still play an important role in the mixed teaching mode, but the application form has changed. In the process of applying traditional teaching resources, teachers should pay more attention to excavate the knowledge, and skillfully design the application way of resources. For example, there is a reading material in the textbook titled as "Thank you, Volunteers!" This reading material mainly introduces different ways of thanking volunteers. Volunteers can be taken as the breakthrough point to refine the theme and help students understand the content and theme of the text. Some complex sentence patterns shall be especially explained, such as "Here are some of the ways posted online to thank volunteers who come to offer help." Teachers shall dig out the "who" attributive clauses, so as to make students understand that "volunteers" serves as is antecedent.

\section{Conclusions}

To sum up, the mixed English teaching model in higher vocational education based on the "Internet plus" can give full play to the advantages of online and offline teaching. What's more, it can improve the degree of pertinence and individualization of English teaching, so as to meet the students' learning and development needs. Through creating U-Learning teaching environment, promoting SPOC curriculum resources and promoting the organic integration of multiple teaching modes, teachers can provide all-round support for students' autonomous learning, so as to implement the student-oriented concept of education, thus upgrading the quality of higher vocational English teaching.

\section{Acknowledgements}

2017-2019 The Research Projects on Higher Vocational Colleges in English Teaching Reform in Xinjiang Uygur Autonomous Region: A Study of Hybrid Model in Higher Vocational English Teaching Under the Background of Internet+ (XJZYYYJG2017G14);2018The Projects of Education and Teaching Reform in Urumqi Vocational University: A Practice Study on Hybrid Model in Higher Vocational English Teaching Based on Blue Ink Cloud Class(18xjg14).

\section{References}

[1] Mckeachie W J. Research on college teaching: The historical background. [J]. Journal of Educational Psychology, 1990, 82(2):189-200.

[2] Lin H. A Meta-Synthesis of Empirical Research on the Effectiveness of Computer-Mediated Communication (CMC) in SLA. [J]. Language Learning \& Technology, 2015, 19(2):85-117.

[3] Li Hua. The Construction of New Diversified Teaching Modes Based on the Training of Workplace English Proficiency-- Research on Vocational Public English Practical Teaching[J]. International Journal of Technology Management, 2013:1-3.

[4] Eckerth, Johannes|Tavakoli, Parveneh. The Effects of Word Exposure Frequency and Elaboration of Word Processing on Incidental L2 Vocabulary Acquisition through Reading. [J]. Language Teaching Research, 2012, 16(2):227-252.

[5] Yoon H G, Yong J J, Kim M. The Challenges of Science Inquiry Teaching for Pre-Service Teachers in Elementary Classrooms: Difficulties on and under the Scene[J]. Research in Science Education, 2012, 42(3):589-608.

[6] Paul H. Smith. Troops to Teaching: lessons from English teaching assistants' experiences of foundation degree study[J]. Journal of Education for Teaching, 2012, 38(5):525-537.

[7] Xing, Xiaohu, Jing. Research of Teaching Reform in Physical Education under the lifelong sports background[J]. International Journal of Technology Management, 2014:23-25. 